\title{
LUMINESCENT THIN FILMS BY THE CHEMICAL AEROSOL DEPOSITION TECHNOLOGY (CADT)
}

F.J. MARTIN, H. ALBERS, P.V. LAMBECK,

G.M.H. VAN DE VELDE and Th.J.A. POPMA

MESA Research Institute, University of Twente, P.O. Box 217, 7500 AE, Enschede, The Netherlands

\section{ABSTRACT}

Zinc sulphide thin films have been deposited with CADT using zinc chloride and zinc acetylacetonate as $\mathrm{zn}$ compounds and thiourea and 1,1,3,3-tetramethylthiourea as $S$ compounds soluted in methanol, ethanol, isopropanol and cellosolve. After optimalization of the deposition process homogeneous layers with a c-axis oriented hexagonal columnar structure with a high density (up to 968) were obtained. Luminescence was observed with films grown above $500^{\circ} \mathrm{C}$. The influence of the hot plate temperature, flow of carrier gas, nozzle geometry, distance nozzle substrate, and volatility of the solvent and reactants on the growth rate, homogenity and density of the film has been shown. Some rules for the selection of the starting compound are given. TG analyses of the reactant compounds was used to compare their volatility and stability.

\section{KEYWORDS}

Aerosol, spray pyrolysis, zns, luminescence, deposition, thin films.

\section{INTRODUCTION}

Thin film deposition techniques are in general expensive technologies, difficult to apply over wide areas. Chemical aerosol deposition technology (CADT) is a relatively cheap technology (no expensive vacuum equipment), easy to operate and applicable over wide areas. The method is based on the pyrolysis of an aerosol, consisting of small droplets of a solution which contains the precursor compounds. Depending on the processing conditions various modes of aerosol decomposition may occur (Lambeck et al., 1986). One of this modes resembles the chemical vapour deposition (CVD) very much. In this mode the aerosol droplets evaporate completely and the vapour reacts on the substrate to form a thin film. CVD is one of the most sophisticate deposition technologies, but also a very expensive one. The film quality of the layers made by CADT is expected to be comparable to those made by CVD because the final process step is the same.

preliminary results (Maatman et al.,1988) showed that luminescent zns layers could be made by CADT. We have improved the geometry of the nozzle, the distance nozzle-substrate and the aerosol flow rate and studied several other reactants, zinc chloride and zinc acetylacetonate as $\mathrm{zn}$ compounds and thiourea and 1,1,3,3-tetramethylthiourea as $s$ compounds, and solvents, methanol, ethanol, isopropanol and cellosolve, to optimize this process.

\section{EXPERIMENTAL PROCEDURE}

A solution of one or more precursor compounds in an organic solvent is nebulized with an ultrasonic generator $(3 \mathrm{MHz})$. The aerosol formed, with droplets of a few microns of diameter, is dragged by a flow of nitrogen (1-5 $l / \mathrm{min}$ ) to the substrate (glass) which is placed on a hot plate (Maatman et al.,1988). The flow is directed by a nozzle perpendicular to the substrate. The substrate is scanned in one direction under the spray nozzle. Two types of rectangular nozzles to spray the aerosol have been used. One type was fitted with a flange (fig.1). The optimal distance between the nozzle and the substrate $(1-5 \mathrm{~mm})$ depended on the spray solution and flow. The concentration of the precursor compounds in the experiments reported here was 0.1 molar and the ratio from the $\mathrm{zn}$ and $\mathrm{s}$ compounds was $1: 1$. 


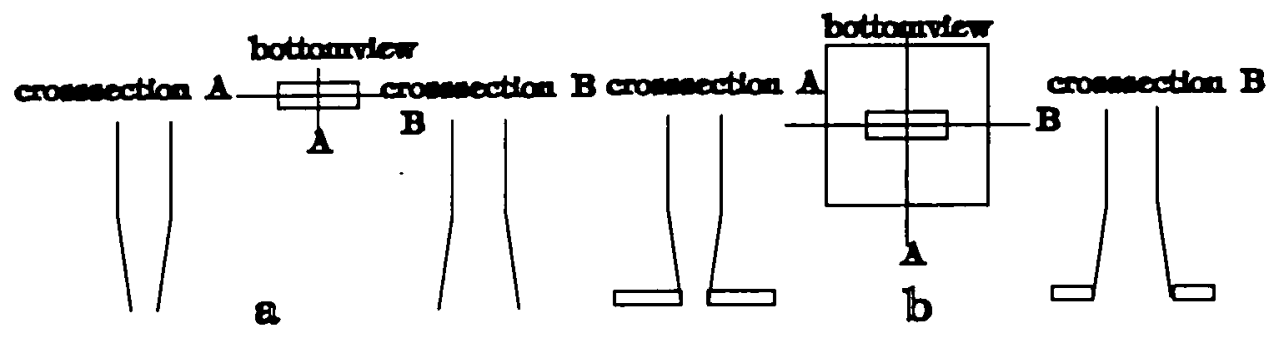

Fig. 1. Nozzle geometry of the two types used:

a) nozzle without flange, b) nozzle with flange.

\section{OPTIMIZATION OF CADT}

The CADT has a lot of controllable parameters, which makes it difficult to optimize a process. To our experience the best procedure consist of the following steps:

- solution choice; reactants and solvent,

- optimization of aerosol generation and transport,

- determine suitable reaction temperature,

- optimization for each temperature of flow conditions near substrate (nozzle-shape, distance nozzle-substrate and flow rate).

Some iteration is often necessary. We will discuss this steps in more detail. The reactants used in CADT must be stable in the air at room temperature (no oxidation, hydrolysis or decomposition). They must be soluble in a suitable solvent. The vapour pressure of the reactants or their decomposition products must be higher than about $10 \mathrm{~Pa}$ at a temperature $100-200^{\circ} \mathrm{C}$ lower than the substrate temperature. The reactivity of this vapour must be just sufficient to give an heterogeneous reaction on the heated substrate. Too high reactivity leads to unwanted gasphase nucleation. A suitable solvent must nebulize well and have a boiling point below about $150^{\circ} \mathrm{C}$. The aerosol in the nozzle must have a narrow size distribution to get a uniform evaporation of the droplets. In our setup this is assured by using an ultrasonic nebulizer and a cyclone impactor coupled to the nozzle. The substrate temperature has to be chosen first for an acceptable deposition rate, further optimization is an iterative process in which also the flow conditions has to be optimized. The aerosol flow over the substrate has to be without turbulence to prevent coalescence and to get reproducible results. To obtain laminar conditions the flow rate has to be high or the flow has to be restricted to a small cross section. We choose for the later approach because a high flow rate will cause a strong cooling of the substrate surface. A small cross section can be achieved by a short distance between nozzle and substrate and further improved by a flat flange on the nozzle parallel to the substrate. Further advantages of a flange are the higher temperature in the reaction zone and that a greater part of the aerosol flows within a layer close to the substrate from which diffusion to the surface is possible.

\section{RESULTS AND DISCUSSION}

Observations during deposition

The area where deposition takes place depends on the solvent volatility, the reactants volatility and the decomposition of the reactants as the following observations showed. For example if methanol, ethanol and isopropanol are used as solvents with zinc chloride and thiourea as reactants, the layer does not grow under the nozzle but it grows under the flange. It starts to grow close to the nozzle with methanol and further for the nozzle with ethanol and isopropanol. The starting diameter of the droplets is almost the same because these solvents have about equal density and surface tension. So a higher boiling point of the solvent results in deposition further from the nozzle. other reactants, zinc acetylacetonate and thiourea, in cellosolve or ethanol form a layer just under the nozzle. This is just a consequence of the higher volatility of zinc acetylacetonate compared with zinc chloride. But not only volatility is important, also reactivity. For example when zinc acetylacetonate is used together with 1,1,3,3-tetramethylthiourea in cellosolve the 
reaction is produced under the flange but not under the nozzle. This has to do with the stability of the sulfur containing molecule. We know that thiourea decomposes at $170-270^{\circ} \mathrm{C}$ (Tomar et al., 1981) but 1,1,3,3-tetramethylthiourea decomposes above its boiling point of $245^{\circ} \mathrm{C}$.

\section{Thermogravimetric analysis}

Vapour pressure data of most organometallic compounds are not available. We have done thermogravimetric analyses (TGA) of the compounds we used. This method does not measure the vapour pressure directly but give information about the weight loss with increasing temperature, so the onset of evaporation or decomposition can be determined. The TGA data of zinc chloride, thiourea and a complex of the two compounds is given in figure 2 .

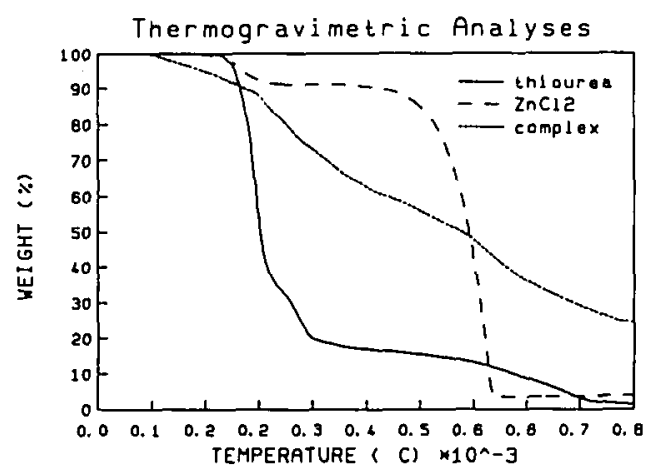

Fig. 2 TGA of zinc chloride, thiourea and complex of these compounds.

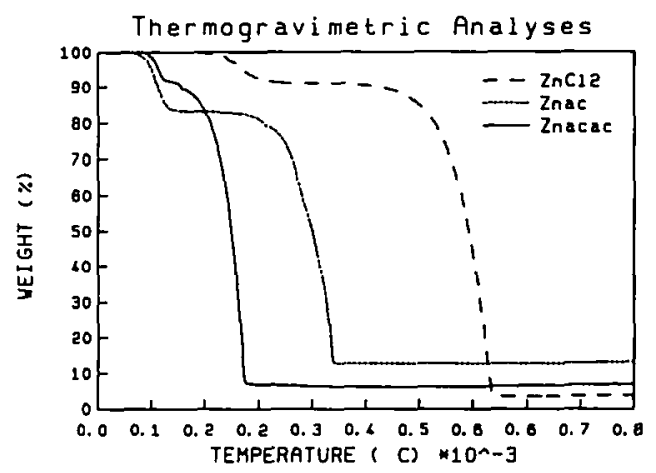

Fig. 3. TGA of zinc acetylacetonate, zinc acetate and zinc chloride.

The curve of the complex is clearly different from those of the single components. A complete explanation of the differences is not simple but an enhancement of the evaporation of zinc containing compounds is obvious. It is known that $z$ ine chloride and thiourea form a complex in solution (Kunchur et a1., 1958). Another example of the application of TGA is given in figure 3 , where we have compared the curves for zinc chloride, zinc acetate and zinc acetylacetonate. An increase of volatility in this order is clear.

\section{Deposited layers}

In the coarse of this work a lot of films have been deposited using different zinc and sulphur compounds and several solvents. The depositions were carried out at temperatures ranging from $375-550^{\circ} \mathrm{C}$. Most of these layers have been characterized with scanning electron microscopy (SEM), $\mathrm{X}$-ray diffraction (XRD) and X-ray fluorescence analysis (XRF). Generally the layers had a hexagonal columnar structure. Beside some $\beta-\mathrm{zns}$ in the initial layer at lower growth temperatures $x$-ray diffraction showed c-axis oriented $\alpha-2 n s$. The density of the layers evaluated from SEM (thickness) and XRF (mass/ $\mathrm{cm}^{2}$ ) data varied from $30-99 \%$, depending on deposition conditions. The growth rate depended strongly on the flow conditions and the substrate temperature. Some characteristic results are reported is table 1.

Table 1. Characteristic examples of deposition results

\begin{tabular}{|c|c|c|c|c|c|c|}
\hline Zn donor & Solvent & $\begin{array}{ll}\text { Temp. } & \left(\begin{array}{ll}0 & \end{array}\right)\end{array}$ & $\begin{array}{l}\text { Dist. } \\
\text { (mm) }\end{array}$ & $\begin{array}{l}\text { Flow } \\
(1 / \mathrm{min})\end{array}$ & $\begin{array}{l}\text { G. rate } \\
(\mathrm{nm} / \mathrm{min})\end{array}$ & $\begin{array}{l}\text { Density } \\
(z)\end{array}$ \\
\hline Zinc chloride & ethanol & 450 & 5 & 3 & 7 & 72 \\
\hline 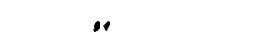 & $\because$ & 550 & 5 & 3 & 27 & 75 \\
\hline . & $\cdots$ & 450 & 2 & 1.8 & 42 & 56 \\
\hline$\cdot$ & : & 550 & 2 & 2.5 & 90 & 81 \\
\hline$\therefore$ & methanol & 550 & 1 & 1.1 & 173 & 96 \\
\hline Zinc acac. & cellosolve & 400 & 2 & 2.5 & 13 & 99 \\
\hline
\end{tabular}


A SEM photograph of an example of a clear columnar layer with the columns separated is showed in figure 4. A picture of a very dense film, which consists according to XRD also of columnar $a-2 n s$ is showed in figure 5 . Films of a thickness up to $10 \mu \mathrm{m}$ have been deposited. The luminescent properties of the layers were not yet studied in detail, but all layers have been activated with UV light of $254 \mathrm{~nm}$. All the layers deposited at 500 and $550^{\circ} \mathrm{C}$ showed a blue luminescence. A few layers were doped with Al and Cu by mixing aluminum and copper acetylacetonate in the spray solution. These doped films showed a light blue luminescence. Visible light emission upon electron irradiation in a SEM could be detected with an EDX detector.

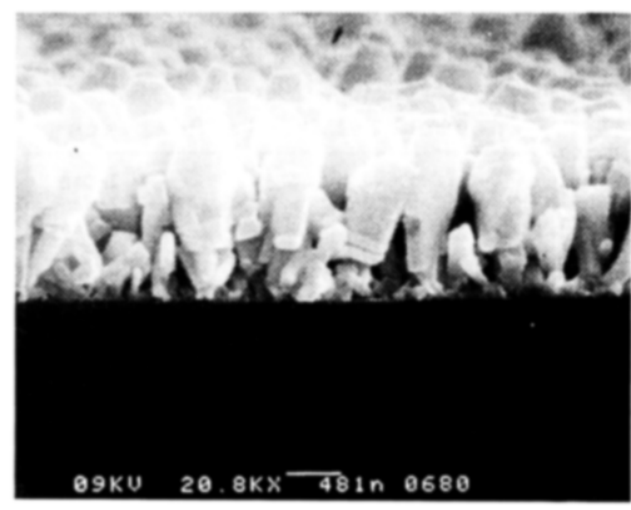

Fig. 4. SEM photograph of a cross section of a zns film made by spraying zinc chloride and thiourea in ethanol at $550^{\circ} \mathrm{C}$. Nozzle distance $5 \mathrm{~mm}$.

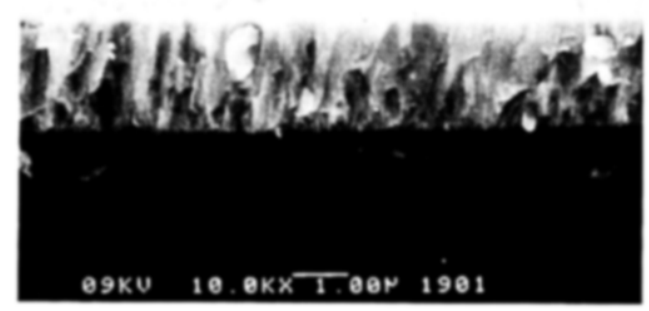

Fig. 5. SEM photograph of a cross section of a zns film made by spraying zinc chloride and thiourea in methanol at $550^{\circ} \mathrm{C}$. Nozzle distance $1 \mathrm{~mm}$.

\section{CONCLUSIONS}

Homogeneous layers of hexagonal $\mathrm{zns}$ with high density (relative density upto 968), crystalline with preferential orientation in the c-axis and thickness of several microns have been deposited by CADT.

Nozzle geometry, flow of carrier gas and distance nozzle-substrate in relation to the reactants and solvent appeared to be key parameters in order to achieve dense homogeneous layers. A setup using a nozzle with a flange on a few millimeters from the substrate appeared to give the best results.

We have demonstrated that zns layers can be made with several precursors and that the optimum deposition temperuture depended on the volatility of the reactants.

TG analysis is a good tool to solve the lack of information of vapour pressure measurements of organometallic compounds. They give also some additional information about the influence of complexation on the volatility of the reaction mixture.

\section{ACKNOWLEDGEMENTS}

We would like to thank Mr. W. de Munnink for a great deal of the experimental work and Mr. A.M. Otter for SEM photographs.

\section{REFERENCES}

Blandenet, G., Court, M. and Y. Lagarde (1981). Thin layers deposited by the pyrosol process. Thin Solid Films, 77, 81-90.

Kunchur, N.R. and M.R. Truter (1958). The crystal structure of dichlorobisthioureazinc. J. Chem. Soc., p. 3478-84.

Lambeck, P.V., Hilderink, L. and Th.J.A. Popma (1986). Thin-layer formation by chemical aerosol deposition. Proc. 2nd Int. Aerosol Conf. Berlin, 964967.

Maatman, D., Gruisinga, W., Lambeck, P.V. and Th.J.A. Popma (1988). Production of thin luminescent films by chemical aerosol deposition technology (CADT). J. Aerosol Sci., 19, 1369-1372.

Tomar, M.S. and F.J. Garcia (1981). Spray pyrolysis in solar cells and gas sensors. Prog. Crystal Growth Charact., 4, 221-248. 